\title{
Diferentes fontes protéicas para a alimentação do jundiá (Rhamdia quelen)
}

\author{
Different protein sources for jundiá (Rhamdia quelen) feeding
}

\author{
Rafael Lazzari $^{1}$ João Radünz Neto ${ }^{2}$ Tatiana Emanuelli ${ }^{3}$ \\ Fabio de Araújo Pedron ${ }^{4}$ Mário Leão Costa ${ }^{4}$ Marcos Eliseu Losekann ${ }^{4}$ \\ Viviani Correia ${ }^{5}$ Vivian Caetano Bochi ${ }^{6}$
}

\section{RESUMO}

O objetivo deste trabalho foi verificar o crescimento e a composição de filés de juvenis de jundiá (Rhamdia quelen) alimentados com diferentes fontes protéicas, durante 60 dias. Utilizaram-se 540 peixes (peso médio inicial $=15,00 \pm 0,62 \mathrm{~g}$, comprimento total inicial $=11,98 \pm 0,35 \mathrm{~cm})$ distribuídos ao acaso em 18 caixas de $280 L$ (30 peixes/caixa) em sistema de recirculação de água. Testaram-se seis tratamentos (com três repetições): CL (farinha de carne e ossos + levedura), SL (farelo de soja + levedura), S (somente farelo de soja), CS (farinha de carne e ossos + farelo de soja), PL (farinha de peixe + levedura) e PS (farinha de peixe + farelo de soja). Foram estimados parâmetros de desempenho (peso, comprimento total, fator de condição, taxa de crescimento específico, taxa de eficiência protéica) aos 30 e 60 dias, composição centesimal e taxas de deposição de proteína e gordura nos filés ao final do experimento. Os parâmetros peso, comprimento total e taxa de crescimento específico foram superiores nos tratamentos compostos pela combinação das farinhas de origem animal (carne e ossos e peixe) com farelo de soja. A quantidade de gordura e proteína depositada no filé dos peixes também foi superior nestes tratamentos (CS e PS). Os rendimentos de carcaça e filé não diferiram entre os tratamentos. A combinação das farinhas de carne e ossos e de peixes com farelo de soja possibilita bom crescimento e maior deposição de proteína e gordura nos filés de juvenis de jundiá.

Palavras-chave: jundiá, crescimento, fontes protéicas, filé Rhamdia quelen.

\begin{abstract}
This study aimed at verifing the growth and fillet composition of jundiá juveniles (Rhamdia quelen) fed with different protein sources, for 60 days. It was used 540 fish (initial weight $=15.00 \pm 0.62 \mathrm{~g}$, initial length $=11.98 \pm 0.35 \mathrm{~cm}$ ) at random distributed in 18 tanks of $280 L$ (30 fish/tank) in a water re-use system. 6 treatments were tested (with 3 repetitions): $C L$ (meat and bone meal + yeast), SL (soybean meal + yeast), $S$ (only soybean meal), CS (meat and bone meal + soybean meal), PL (fish meal + yeast) and PS (fish meal + soybean meal). They were dear development parameters (weight, total length, condition factor, specific growth rate, protein efficiency ratio) to the 30 and 60 days, centesimal composition and protein and fat deposition in the filets at the end of the experiment. The parameters weight, total length and specific growth rate were higher in the treatments composed by the combination of the feedstufs of animal origin (meat and bone and fish meal) with soybean meal. The fat and protein deposited in the filet of the fish was also higher in these treatments (CS and PS). The carcass and filet yeld didn't differ among the treatments. This concluded that the combination of meat, and bone, and fish meal with soybean meal make good growth and higher protein and fat deposition in the filets of jundiá juveniles.
\end{abstract}

Key words: jundiá, growth, protein sources, fillet, Rhamdia quelen.

${ }^{1}$ Programa de Pós-graduação em Zootecnia, UFSM, Santa Maria, RS, Brasil.

${ }^{2}$ Departamento de Zootecnia, UFSM, Santa Maria, RS, Brasil. E-mail: jradunzneto@smail.ufsm.br. Autor para correspondência.

${ }^{3}$ Departamento de Tecnologia e Ciência dos alimentos, UFSM, Santa Maria, RS, Brasil.

${ }^{4}$ Programa de Pós- graduação em Zootecnia, UFSM, Santa Maria, RS, Brasil.

${ }^{5}$ Curso de Zootecnia, UFSM, Santa Maria, RS, Brasil.

${ }^{6}$ Curso de Fármácia e Bioquímica, UFSM, Santa Maria, RS, Brasil. 


\section{INTRODUÇÃO}

Ojundiá (Rhamdia quelen) é um Siluriforme de hábito alimentar onívoro, encontrado desde o sul do México até a Argentina (GOMES et al., 2000), que apresenta carne de sabor agradável e bem aceita pelos consumidores. No Brasil, sua criação está mais concentrada nos estados da Região Sul, principalmente no Rio Grande do Sul.

A busca de uma ração balanceada que proporcione maior crescimento aos peixes passa pela utilização adequada das melhores fontes protéicas disponíveis. Isso objetiva reduzir o custo das rações sem diminuição do desempenho dos peixes (TACHIBANA \& CASTAGNOLLI, 2003). Para isso, devem-se utilizar alimentos com bom aporte de nutrientes, homogeneidade de composição e disponibilidade constante no mercado (LOVELL, 1991).

Dos alimentos de origem vegetal, o farelo de soja é considerado o de melhor composição, sendo utilizado em rações para muitas espécies de peixes (LOVELL, 1988). Pode substituir até 50\% da farinha de peixe em dietas para espécies carnívoras e até $94 \%$ para onívoras (REFSTIE et al., 1998). Para alevinos de catfish (Ictalurus punctatus), dietas com 33\% de proteína bruta e $2900 \mathrm{kcal}$ de ED/kg compostas somente por farelo de soja proporcionaram resultados similares a peixes alimentados somente com farinha de peixe (WEBSTER et al., 1992).

A levedura (Saccharomyces cerevisiae) é um alimento com bom teor protéico, variando de 37 até $45 \%$ de proteína bruta, muito utilizada em rações para organismos aquáticos. Para o jundiá, alguns trabalhos mostraram bom ganho em peso para larvas e alevinos alimentados com rações em que este ingrediente foi um dos constituintes da base protéica (PIAIA \& RADÜNZ NETO, 1997; COLDEBELLA \& RADÜNZ NETO, 2002).

A farinha de peixe é a fonte protéica mais comumente utilizada em rações para peixes (TACON, 1993; WEBSTER et al., 1995). Possui altos teores protéicos e bom perfil de aminoácidos, ocorrendo grande variabilidade de composição, devido à heterogeneidade das matérias primas utilizadas na sua preparação. Apesar do alto valor nutritivo e boa palatabilidade, o elevado custo encarece o preço final da ração (KIM et al., 1997).

A composição química dos peixes, principalmente a gordura, pode variar consideravelmente devido a fatores como: espécie, idade do animal, sexo, estação do ano e fatores ambientais (GERI et al., 1995; SHIRAI et al., 2002). A qualidade da dieta, bem como as variações nos teores protéicos e lipídicos também influenciam diretamente na composição dos filés dos peixes (JUSTI et al., 2003). Para o jundiá, faltam trabalhos que avaliem as características qualitativas da carne.

Desta forma, o objetivo deste trabalho foi verificar o crescimento e a composição de filés de juvenis de jundiá (Rhamdia quelen) alimentados com diferentes fontes protéicas.

\section{MATERIAL E MÉTODOS}

O presente trabalho realizou-se no Laboratório de Nutrição de Peixes da Universidade Federal de Santa Maria, no período de Janeiro a Março de 2004. O experimento teve duração de 60 dias, utilizando-se um sistema de recirculação de água composto de 18 caixas de polipropileno (280L), com temperatura controlada e sistema de aeração tipo "Venturi" (RADÜNZ NETO et al., 1987). Utilizaram-se 540 juvenis de jundiá (Rhamdia quelen) (peso inicial: $15,00 \pm 0,62 \mathrm{~g}, \quad$ comprimento total inicial $=11,98 \pm 0,35 \mathrm{~cm}$ ), obtidos através de reprodução induzida. Cada unidade experimental foi constituída por uma caixa que continha 30 peixes.

Foram testadas seis dietas (com três repetições) compostas pela combinação de fontes protéicas: farelo de soja, levedura, farinha de carne e ossos e farinha de peixe (Tabela 1). Estas foram assim denominadas: CL (farinha de carne e ossos + levedura), SL (farelo de soja + levedura), S (somente farelo de soja), CS (farinha de carne e ossos + farelo de soja), PL (farinha de peixe + levedura) e PS (farinha de peixe + farelo de soja).

A alimentação foi fornecida aos peixes duas vezes ao dia ( 9 e 17h), até a saciedade aparente. Antes de cada alimentação, foram retirados os resíduos do dia anterior por meio de sifonagem. Diariamente foram aferidos os parâmetros físico-químicos da água do sistema de criação.

Antes do início do experimento, 30 peixes foram separados aleatoriamente, para avaliação da composição centesimal inicial de filés. Do restante do lote de peixes, foram, também ao acaso, retirados os 540 peixes para compor o experimento. Para a realização de análises da composição centesimal dos filés, utilizaram-se três peixes por unidade experimental (nove por tratamento).

Os parâmetros estimados foram: Comprimento total (CT): medida da porção anterior da cabeça até o final da nadadeira caudal, em cm; Peso (P): peso final obtido ao final de cada período, em gramas; Sobrevivência (S): percentagem de sobreviventes em relação ao número inicial de peixes 
Tabela 1 - Composição das rações experimentais (\%).*

\begin{tabular}{|c|c|c|c|c|c|c|}
\hline \multirow{2}{*}{ Ingrediente } & \multicolumn{6}{|c|}{ Tratamentos } \\
\hline & $\mathrm{CL}^{1}$ & $\mathrm{SL}^{2}$ & $\mathrm{~S}^{3}$ & $\mathrm{CS}^{4}$ & $\mathrm{PL}^{5}$ & $\mathrm{PS}^{6}$ \\
\hline Levedura & 28 & 33,27 & - & - & 25,92 & - \\
\hline Farinha de carne e ossos & 38,53 & - & - & 30 & - & - \\
\hline Farinha de peixe & - & - & - & - & 30,06 & 22,48 \\
\hline Farelo de soja & - & 33,27 & 68,53 & 32 & - & 30 \\
\hline Milho & 15 & 13,44 & 12,45 & 16,95 & 20 & 19,5 \\
\hline Farelo trigo & 8 & 10 & 10 & 8,03 & 15 & 18 \\
\hline Óleo de canola & 7,45 & 7 & 6 & 10 & 6 & 7 \\
\hline Sal comum & 1 & 1 & 1 & 1 & 1 & 1 \\
\hline Fosfato Bicálcico & 1 & 1 & 1 & 1 & 1 & 1 \\
\hline Mistura vitamínica e mineral ${ }^{1}$ & 1 & 1 & 1 & 1 & 1 & 1 \\
\hline \multirow[t]{2}{*}{ Etoxiquina $^{2}$} & 00,2 & 00,2 & 00,2 & 00,2 & 00,2 & 0,02 \\
\hline & & \multicolumn{5}{|c|}{ Composição centesimal (\%) } \\
\hline \multicolumn{7}{|l|}{ Nutrientes } \\
\hline Proteína bruta $^{4}$ & 34,6 & 32,1 & 33,0 & 34,4 & 32,9 & 31,9 \\
\hline Energia digestível ${ }^{3}(\mathrm{kcal} / \mathrm{kg})$ & 3420 & 3174 & 3090 & 3451 & 3267 & 3250 \\
\hline Matéria Mineral $^{4}$ & 13,2 & 5,2 & 6,2 & 12,9 & 9,9 & 10,7 \\
\hline Extrato etéreo $^{4}$ & 12,7 & 8,0 & 7,2 & 16,4 & 9,8 & 11,4 \\
\hline Fibra bruta $^{4}$ & 1,8 & 3,1 & 4,2 & 3,6 & 1,8 & 3,6 \\
\hline Umidade $^{4}$ & 6,9 & 7,9 & 8,9 & 5,5 & 6,5 & 8,0 \\
\hline Cálcio $^{4}$ & 3,4 & 1,3 & 1,5 & 3,0 & 2,1 & 2,1 \\
\hline Fósforo ${ }^{4}$ & 2,0 & 0,7 & 0,8 & 1,8 & 1,5 & 1,5 \\
\hline Arginina $^{5}$ & 1,7 & 1,8 & 2,5 & 2,1 & 1,7 & 2,1 \\
\hline Fenilalanina $^{5}$ & 1,0 & 1,4 & 1,8 & 1,2 & 1,2 & 1,4 \\
\hline Histidina $^{5}$ & 0,5 & 0,7 & 0,9 & 0,6 & 0,9 & 1,0 \\
\hline Isoleucina $^{5}$ & 1,0 & 1,4 & 1,6 & 1,0 & 1,3 & 1,3 \\
\hline Lisina $^{5}$ & 2,1 & 2,0 & 2,1 & 1,9 & 2,1 & 2,0 \\
\hline Leucina $^{5}$ & 1,8 & 2,2 & 2,6 & 1,9 & 2,2 & 2,3 \\
\hline Metionina+cistina $^{5}$ & 0,8 & 0,8 & 1,0 & 0,8 & 0,9 & 0,9 \\
\hline Treonina $^{5}$ & 1,1 & 1,4 & 1,4 & 1,0 & 1,4 & 1,2 \\
\hline Triptofano ${ }^{5}$ & 0,1 & 0,2 & 0,4 & 0,2 & 0,2 & 0,4 \\
\hline Valina $^{5}$ & 1,3 & 1,6 & 1,7 & 1,3 & 1,5 & 1,5 \\
\hline
\end{tabular}

*Dietas ajustadas ao experimento de acordo com COLDEBELLA \& RADÜNZ NETO (2002).

${ }^{1}$ Composição da mistura vitamínica e mineral (por kg de produto): Ác. Fólico: 400mg, Ác. Nicotínico: 14000mg, Ác. Pantotênico: 8000mg, Cobalto: 1500mg, Cobre: 15000mg, Colina: 1500mg, Ferro: 50000mg, Iodo: 700mg, Manganês: 23000mg, Selênio: 250mg, Vit.A: 6000000UI, Vit. B1: 1400mg, Vit. B2: 3375mg, Vit. B6: 4830mg, Vit. B12: 5000mcg, Vit. C: 25000mg, Vit. D3: 530000UI, Vit. E: 22500 mg, Vit. K3: 5000mg, Zinco: 40000mg.

${ }^{2}(32 \%$ etoxiquina, $18 \%$ propil-galato, $50 \%$ veículo-talco).

${ }^{3} \mathrm{ED}=[(23,6 \mathrm{~kJ} . g-1 \times$ \% PROT. x 0,9) + (39,8kJ.g-1 x \%LIP. x 0,85) + (17,2 kJ.g-1 x \%CHO x 0,5)]/100.

(JOBLING, 1995). (1kcal=4,184kJ).

${ }^{4}$ Valores analisados.

${ }^{5}$ Valores calculados (obtidos em banco de dados da Ajinomoto Biolatina Ind. e Com. Ltda., Brasil).

Tratamentos: ${ }^{1} \mathrm{CL}$ : farinha de carne e ossos + levedura; ${ }^{2} \mathrm{SL}$ : farelo de soja + levedura; ${ }^{3} \mathrm{~S}$ : somente farelo de soja; ${ }^{4} \mathrm{CS}$ : farinha de carne e ossos + farelo de soja; ${ }^{5} \mathrm{PL}$ : farinha de peixe + levedura: ${ }^{6} \mathrm{PS}$ : farinha de peixe + farelo de soja

em cada tratamento; Taxa de crescimento específico (TCE): expresso em \%/dia, calculado segundo a fórmula: $\left\{\left[\log _{n}\right.\right.$ (Peso final $)-\log _{n}($ Peso inicial $\left.)\right] /$ período (60 ou 90 dias) \} x 100; Fator de condição (FC): (Peso x 100) / (Comprimento total $\left.{ }^{3}\right)$; Rendimento de carcaça (RC): diferença entre o peso inteiro e o peso eviscerado, com as brânquias, expresso em percentagem (MELO et al. 2002); Conversão alimentar aparente (CAA): quantidade de alimento consumido / ganho em peso obtido; Taxa de eficiência protéica (TEP): ganho em peso / quantidade de proteína consumida; Consumo diário (CD): Consumo no período/ [(peso final + peso inicial)/2] / dias x 100, expresso em \% PV/dia.

As cinzas e umidade do filé foram determinadas através da metodologia descrita nas Normas analíticas do INSTITUTO ADOLFO LUTZ
(1985). A proteína total foi determinada pelo método de KJELDAHL (N=6,25) e os lipídios segundo metodologia descrita por LANARA (1981). O teor de carboidratos foi calculado por diferença. A partir da composição centesimal, foram calculadas (CAMARGO et al., 1999): proteína bruta total depositada (PBTD): total de proteína bruta depositada no filé (TPDF): gordura total depositada (GTD): total de gordura depositada no filé (TGDF): GTD/D x 1000.

O delineamento experimental utilizado foi o inteiramente casualizado. Os dados obtidos foram analisados por análise de variância e as médias comparadas pelo teste de DUNCAN $(\mathrm{P}<0,05)$. Utilizouse, para as análises, o pacote estatístico "SAS" (1997).

Ciência Rural, v.36, n.1, jan-fev, 2006. 


\section{RESULTADOS E DISCUSSÃO}

Os parâmetros de qualidade de água do sistema de criação foram: temperatura $\left(26,85 \pm 1,02^{\circ} \mathrm{C}\right)$, amônia total $(0,50 \pm 0,22 \mathrm{ppm})$, nitrito $(0,06 \pm 0,01 \mathrm{ppm})$, alcalinidade $\left(48,96 \pm 13,40 \mathrm{mgCaCO}_{3} / \mathrm{L}\right), \mathrm{pH}(7,30 \pm 0,26)$ e oxigênio dissolvido $(5,53 \pm 0,62 \mathrm{ppm})$.

A tabela 2 mostra o peso dos juvenis aos 30 dias e ao final do experimento (60 dias). Os peixes alimentados com farelo de soja combinado com a farinha de carne e ossos diferiram significativamente dos demais tratamentos $(85,59 \mathrm{~g})$. Observou-se, aos 60 dias, menor peso nos jundiás do tratamento composto somente por farelo de soja $(43,65 \mathrm{~g})$.

Este menor crescimento deve-se ao elevado nível de incorporação de farelo de soja nesta dieta (68\%), que contém componentes que causam distúrbios nos processos digestivos (KAUSHIK et al., 1995). Diferentes fatores anti-nutricionais têm sido identificados no farelo de soja, como inibidores de proteases, lectinas e proteínas antigênicas (MOYANO et al., 1992). A tolerância à utilização deste ingrediente depende muito da espécie e também do tempo de alimentação. Para o jundiá, estudos demonstraram que o nível ótimo de incorporação deste ingrediente é de 36,4\% (COLDEBELLA \& RADÜNZ NETO, 2002). PONGMANEERAT et al. (1993) observaram decréscimo no crescimento de carpas alimentadas com rações contendo níveis de farelo de soja acima de 30\%.

A conversão alimentar aparente (CAA), aos 30 dias, foi melhor nos jundiás alimentados com rações contendo farinhas de origem animal (tabela 2). Ao final do experimento, os peixes do tratamento (CS) tiveram melhor conversão $(1,42: 1)$, diferindo estatisticamente dos demais. Pior conversão alimentar aparente foi verificada nos peixes alimentados com a ração à base de farelo de soja somente (S).

Com tilápias, EL SAYED (1998) observou que a utilização de farinha de carne e ossos proporciona bom crescimento aos peixes. O mesmo autor salienta que ingredientes de origem animal possuem grande valor nutricional, principalmente em relação ao valor biológico da proteína, o que melhora a utilização do alimento. Deve-se destacar que não existem trabalhos

Tabela 2. Parâmetros zootécnicos dos jundiás aos 30 e 60 dias experimentais.

\begin{tabular}{|c|c|c|c|c|c|c|c|}
\hline Parâmetro & $\mathrm{CL}^{1}$ & $\mathrm{SL}^{2}$ & $\mathrm{~S}^{3}$ & $\mathrm{CS}^{4}$ & $\mathrm{PL}^{5}$ & $\mathrm{PS}^{6}$ & $\mathrm{CV}$ \\
\hline & & & & 30 dias & & & \\
\hline $\mathrm{CT}(\mathrm{cm})$ & $15,7^{\mathrm{ab}}$ & $14,8^{\mathrm{bc}}$ & $14,1^{\mathrm{c}}$ & $16,2^{\mathrm{a}}$ & $15,6^{\mathrm{ab}}$ & $16,3^{\mathrm{a}}$ & 3,9 \\
\hline $\mathrm{P}(\mathrm{g})$ & $37,5^{\mathrm{abc}}$ & $32,8^{\mathrm{bc}}$ & $27,5^{\mathrm{c}}$ & $43,2^{\mathrm{ab}}$ & $42,6^{\mathrm{ab}}$ & $45,9^{\mathrm{a}}$ & 5,9 \\
\hline CAA & $1,2^{\mathrm{c}}$ & $1,4^{\mathrm{b}}$ & $1,6^{\mathrm{a}}$ & $1,2^{\mathrm{c}}$ & $1,2^{\mathrm{c}}$ & $1,1^{\mathrm{d}}$ & 3,7 \\
\hline TCE (\%/dia) & $2,9^{\mathrm{ab}}$ & $2,6^{\mathrm{bc}}$ & $2,0^{\mathrm{c}}$ & $3,3^{\mathrm{ab}}$ & $3,6^{\mathrm{a}}$ & $3,8^{\mathrm{a}}$ & 15,5 \\
\hline $\mathrm{FC}$ & $0,9^{\mathrm{b}}$ & $0,9^{\mathrm{b}}$ & $0,9^{\mathrm{b}}$ & $1,0^{\mathrm{b}}$ & $1,1^{\mathrm{a}}$ & $1,0^{\mathrm{ab}}$ & 4,8 \\
\hline $\mathrm{S}(\%)$ & $100^{\mathrm{a}}$ & $100^{\mathrm{a}}$ & $100^{\mathrm{a}}$ & $100^{\mathrm{a}}$ & $100^{\mathrm{a}}$ & $100^{\mathrm{a}}$ & - \\
\hline $\mathrm{RC}(\%)$ & $81,1^{\mathrm{ab}}$ & $80,7^{\mathrm{ab}}$ & $81,0^{\mathrm{ab}}$ & $79,8^{\mathrm{b}}$ & $81,9^{\mathrm{a}}$ & $81,2^{\mathrm{ab}}$ & 1,7 \\
\hline $\mathrm{RF}(\%)$ & $38,0^{\mathrm{a}}$ & $38,5^{\mathrm{a}}$ & $41,6^{\mathrm{a}}$ & $37,7^{\mathrm{a}}$ & $41,1^{\mathrm{a}}$ & $39,9^{\mathrm{a}}$ & 7,9 \\
\hline TEP & $1,5^{\mathrm{b}}$ & $1,4^{\mathrm{b}}$ & $1,3^{\mathrm{b}}$ & $1,9^{\mathrm{a}}$ & $1,7^{\mathrm{ab}}$ & $1,9^{\mathrm{a}}$ & 6,3 \\
\hline $\mathrm{CD}(\% / \mathrm{PV})$ & $3,1^{\mathrm{b}}$ & $3,3^{\mathrm{a}}$ & $2,8^{\mathrm{c}}$ & $\begin{array}{l}3,0^{\mathrm{bc}} \\
60 \text { dias }\end{array}$ & $3,1^{\mathrm{b}}$ & $2,9^{\mathrm{bc}}$ & 3,7 \\
\hline $\mathrm{CT}(\mathrm{cm})$ & $19,9^{\mathrm{bc}}$ & $19,1^{\text {cd }}$ & $17,0^{\mathrm{e}}$ & $21,6^{\mathrm{a}}$ & $18,8^{\mathrm{d}}$ & $20,5^{\mathrm{b}}$ & 2,8 \\
\hline$P(g)$ & $69,3^{\mathrm{b}}$ & $62,9^{\mathrm{b}}$ & $43,6^{\mathrm{c}}$ & $85,5^{\mathrm{a}}$ & $66,7^{\mathrm{b}}$ & $72,6^{\mathrm{ab}}$ & 11,7 \\
\hline CAA & $1,6^{\mathrm{bc}}$ & $1,7^{\mathrm{b}}$ & $1,9^{\mathrm{a}}$ & $1,4^{\mathrm{d}}$ & $1,6^{\mathrm{bc}}$ & $1,5^{\mathrm{d}}$ & 3,9 \\
\hline TCE (\%/dia) & $2,4^{\mathrm{ab}}$ & $2,4^{\mathrm{b}}$ & $1,7^{\mathrm{c}}$ & $2,8^{\mathrm{a}}$ & $2,5^{\mathrm{ab}}$ & $2,6^{\mathrm{ab}}$ & 7,4 \\
\hline $\mathrm{FC}$ & $0,9^{\mathrm{ab}}$ & $0,9^{\mathrm{ab}}$ & $0,9^{\mathrm{ab}}$ & $0,8^{\mathrm{b}}$ & $1,0^{\mathrm{a}}$ & $0,8^{\mathrm{b}}$ & 7,3 \\
\hline $\mathrm{S}(\%)$ & $100^{\mathrm{a}}$ & $98,7^{\mathrm{a}}$ & $100^{\mathrm{a}}$ & $100^{\mathrm{a}}$ & $98,7^{\mathrm{a}}$ & $96,3^{\mathrm{a}}$ & 2,0 \\
\hline $\mathrm{RC}(\%)$ & $80,7^{\mathrm{a}}$ & $82^{\mathrm{a}}$ & $82^{a}$ & $80,6^{\mathrm{a}}$ & $80^{\mathrm{a}}$ & $80,7^{\mathrm{a}}$ & 5,4 \\
\hline $\mathrm{RF}(\%)$ & $34,7^{\mathrm{a}}$ & $34,3^{\mathrm{a}}$ & $37,3^{\mathrm{a}}$ & $36,0^{\mathrm{a}}$ & $37,7^{\mathrm{a}}$ & $40,2^{\mathrm{a}}$ & 6,9 \\
\hline TEP & $1,6^{\mathrm{c}}$ & $1,5^{\mathrm{c}}$ & $1,3^{\mathrm{d}}$ & $1,9^{\mathrm{a}}$ & $1,6^{\mathrm{bc}}$ & $1,8^{\mathrm{ab}}$ & 4,9 \\
\hline $\mathrm{CD}(\% / \mathrm{PV})$ & $3,8^{\mathrm{ab}}$ & $4,0^{\mathrm{a}}$ & $3,6^{\mathrm{bc}}$ & $3,5^{\mathrm{c}}$ & $3,8^{\mathrm{ab}}$ & $3,7^{\mathrm{abc}}$ & 4,0 \\
\hline
\end{tabular}

Médias com letras diferentes, na linha, diferem estatisticamente pelo teste de Duncan $(\mathrm{P}<0,05)$

Parâmetros: CT: comprimento total; P: peso médio; CAA: conversão alimentar aparente; TCE: taxa de crescimento específico; FC: fator de condição; S: sobrevivência; RC:rendimento de carcaça; RF:rendimento de filé; TEP: taxa de eficiência protéica; CD: consumo diário; CV: coeficiente de variação.

Tratamentos:

${ }^{1}$ CL: farinha de carne e ossos + levedura;

${ }^{2} \mathrm{SL}$ : farelo de soja + levedura;

${ }^{3} \mathrm{~S}$ : somente farelo de soja;

${ }^{4} \mathrm{CS}$ : farinha de carne e ossos + farelo de soja;

${ }^{5} \mathrm{PL}$ : farinha de peixe + levedura;

${ }^{6} \mathrm{PS}$ : farinha de peixe + farelo de soja

Ciência Rural, v.36, n.1, jan-fev, 2006. 
específicos de nutrição com o jundiá, o que dificulta a comparação dos dados obtidos.

Na tabela 2, estão descritos os demais resultados de desempenho dos peixes. Em relação à sobrevivência não ocorreu diferença significativa entre os tratamentos $(\mathrm{P}>0,05)$. Aos 60 dias, o comprimento total (CT) dos peixes do tratamento CS (carne + soja) foi superior aos demais $(21,60 \mathrm{~cm})$.

A taxa de crescimento específico foi superior nos peixes alimentados com farinha de carne e farelo de soja (CS), que tiveram uma TCE de 2,80\%/dia, superior aos peixes dos tratamentos sem fontes de origem animal (SL e S). Com alevinos de jundiá (1g) alimentados com dietas semi-purificadas, MEYER \& FRACALOSSI (2004) obtiveram TCE de 1,8 a 2,60\%/ dia, valores inferiores aos obtidos neste trabalho, mesmo sendo peixes de menor tamanho.

As melhores taxas de eficiência protéica foram verificadas nos tratamentos contendo farelo de soja e farinha de carne e ossos $(1,90)$ e também com farinha de peixe $(1,83)$. O consumo diário de alimento (CD), variou de 3,54 (tratamento CS) até 4,04\% (tratamento SL). Em relação ao consumo, esperava-se que as dietas contendo farinhas de origem animal fossem mais consumidas, pois são classificadas como de alta atratopalatabilidade (PEREIRA-DA-SILVA \& PEZZATO, 2000).

Não houve diferença significativa entre os valores de rendimento de carcaça, que, em todos os tratamentos, foram iguais ou superiores a $80 \%$. Estes valores são semelhantes aos obtidos por MELO et al. (2002), que avaliaram diferentes fontes de lipídios em juvenis de jundiá. Os valores de rendimento de filé (RF) variaram de 34 a $41 \%$, porém não ocorreu diferença significativa entre os tratamentos. $\mathrm{O}$ fator de condição, variável que demonstra a condição corporal do peixe, foi inferior nos peixes alimentados com as dietas contendo farinhas de origem animal e farelo de soja em sua composição (CS e PS).

Na tabela 3, encontram-se os valores da análise centesimal e taxas de deposição de proteína e gordura nos filés dos jundiás ao final do experimento. A quantidade de proteína do filé dos peixes alimentados com a dieta contendo farinha de carne e ossos mais levedura de cana $(\mathrm{CL})$ foi superior $(\mathrm{P}<0,05)$ em relação à análise da amostra inicial.

Entretanto não ocorreu diferença significativa entre os demais tratamentos testados. As menores quantidades de lipídios no filé foram observadas nos peixes dos tratamentos SL (farelo de soja e levedura) e S (farelo de soja). A quantidade de cinzas não diferiu entre os tratamentos, porém foi superior em relação à análise inicial. Observou-se maior deposição de proteína e gordura no filé dos peixes alimentados com rações contendo farinhas de origem animal (carne e ossos ou peixes).

A utilização de farelo de soja na ração para alevinos de catfish acarretou menor deposição lipídica

Tabela 3 - Composição centesimal (\%) e taxas de deposição de proteína e gordura nos filés dos jundiás ao final do experimento.*

\begin{tabular}{|c|c|c|c|c|c|c|c|c|}
\hline Parâmetro & Inicial & ${ }^{1} \mathrm{CL}$ & ${ }^{2} \mathrm{SL}$ & ${ }^{3} \mathrm{~S}$ & ${ }^{4} \mathrm{CS}$ & ${ }^{5} \mathrm{PL}$ & ${ }^{6} \mathrm{PS}$ & $\mathrm{CV}$ \\
\hline Umidade & $76,6^{\mathrm{a}}$ & $74,0^{\mathrm{c}}$ & $76,4^{\mathrm{a}}$ & $76,0^{\mathrm{ab}}$ & $74,6^{\text {bc }}$ & $75,7^{\mathrm{ab}}$ & $76,8^{\mathrm{a}}$ & 1,5 \\
\hline Proteína Bruta & $16,4^{\mathrm{b}}$ & $18,4^{\mathrm{a}}$ & $17,6^{\mathrm{ab}}$ & $17,8^{\mathrm{ab}}$ & $17,4^{\mathrm{ab}}$ & $17,8^{\mathrm{ab}}$ & $17,6^{\mathrm{ab}}$ & 5,8 \\
\hline Lipídios & $5,6^{\mathrm{ab}}$ & $6,0^{\mathrm{a}}$ & $3,6^{\mathrm{c}}$ & $3,8^{\mathrm{c}}$ & $6,5^{\mathrm{a}}$ & $4,7^{\mathrm{bc}}$ & $4,1^{\mathrm{c}}$ & 4,5 \\
\hline Cinzas & $1,0^{\mathrm{b}}$ & $1,3^{\mathrm{a}}$ & $1,4^{\mathrm{a}}$ & $1,3^{\mathrm{a}}$ & $1,2^{\mathrm{a}}$ & $1,4^{\mathrm{a}}$ & $1,3^{\mathrm{a}}$ & 3,2 \\
\hline \multirow[t]{2}{*}{ Carboidratos } & $0,4^{\mathrm{ab}}$ & $0,2^{\mathrm{b}}$ & $1,1^{\mathrm{a}}$ & $1,1^{\mathrm{a}}$ & $0,2^{\mathrm{b}}$ & $0,5^{\mathrm{ab}}$ & $0,3^{\mathrm{b}}$ & 7,8 \\
\hline & \multicolumn{8}{|c|}{ Taxas de deposição de proteína e gordura } \\
\hline $\operatorname{PBTD}(\mathrm{g})$ & & $3,0^{\mathrm{cd}}$ & $3,5^{\mathrm{bc}}$ & $2,1^{\mathrm{d}}$ & $4,7^{\mathrm{a}}$ & $3,8^{\mathrm{bc}}$ & $4,2^{\mathrm{ab}}$ & 14,8 \\
\hline TPDF (mg/dia) & & $51,4^{\mathrm{cd}}$ & $58,4^{\text {bc }}$ & $34,9^{d}$ & $79,3^{\mathrm{a}}$ & $63,9^{\mathrm{bc}}$ & $71,3^{\mathrm{ab}}$ & 14,8 \\
\hline GTD (g) & & $3,7^{\mathrm{c}}$ & $4,1^{\mathrm{bc}}$ & $2,7^{\mathrm{d}}$ & $5,4^{\mathrm{a}}$ & $4,4^{\mathrm{bc}}$ & $4,8^{\mathrm{ab}}$ & 12,7 \\
\hline $\begin{array}{l}\text { TGDF } \\
\text { (mg/dia) }\end{array}$ & & $62,2^{\mathrm{c}}$ & $68,7^{\mathrm{bc}}$ & $45,2^{\mathrm{d}}$ & $90,3^{\mathrm{a}}$ & $73,7^{\mathrm{bc}}$ & $81,3^{\mathrm{ab}}$ & 12,7 \\
\hline
\end{tabular}

Médias com letras diferentes, na linha, diferem estatisticamente pelo teste de Duncan $(\mathrm{P}<0,05)$

*Valores expressos na matéria natural.

Parâmetros: PBTD: proteína bruta total depositada; TPDF: total de proteína bruta depositada no filé; GTD: gordura total depositada; TGDF: total de gordura depositada no filé; CV: coeficiente de variação.

Tratamentos:

${ }^{1} \mathrm{CL}$ : farinha de carne e ossos + levedura;

${ }^{2} \mathrm{SL}$ : farelo de soja + levedura;

${ }^{3} \mathrm{~S}$ : somente farelo de soja;

${ }^{4} \mathrm{CS}$ : farinha de carne e ossos + farelo de soja;

${ }^{5} \mathrm{PL}$ : farinha de peixe + levedura;

${ }^{6} \mathrm{PS}$ : farinha de peixe + farelo de soja

Ciência Rural, v.36, n.1, jan-fev, 2006. 
na carcaça, não alterando a quantidade de proteína em relação a dietas contendo níveis elevados de farinhas de origem animal (farinha de peixe) (MOHSEN \& LOVELL, 1990).

As taxas de deposição de proteína e gordura depositadas no filé dependem muito da matéria-prima utilizada que, no caso das farinhas de origem animal, possuem grande variação de composição. Juvenis de catfish, alimentados com farelo de canola, não apresentaram diferenças $(\mathrm{P}<0,05)$ nas quantidades de gordura e proteína depositada na carcaça (WEBSTER et al., 1997). KIM et al. (1997) observaram aumento significativo na deposição de lipídios na carcaça de juvenis de carpa comum (Cyprinus carpio) alimentados com farelo de soja integral durante 30 dias.

Mais estudos deverão ser realizados para encontrar níveis ótimos de inclusão de farelo de soja e das farinhas de origem animal testadas neste trabalho. De acordo com os resultados obtidos neste estudo, conclui-se que a combinação de farelo de soja com farinha de carne e ossos ou farinha de peixe proporciona bom desenvolvimento e maior deposição de proteína e gordura no filé de juvenis de jundiá.

\section{AGRADECIMENTOS E APRESENTAÇÃO}

À Coordenação de Aperfeiçoamento de Pessoal de Ensino Superior (CAPES) pelo fornecimento de bolsa de estudos ao primeiro autor.

Aos estagiários e funcionários do Laboratório de Nutrição de Peixes da Universidade Federal de Santa Maria pelo auxílio na preparação das instalações experimentais

Às empresas Prónutra do Brasil, Vitagri Nutrição Animal e Zillo Lorenzetti Ltda. pelo fornecimento de ingredientes para a elaboração dos alimentos.

Ao professor José Henrique Souza da Silva pela contribuição e apoio no planejamento experimental e análises estatísticas.

Parte da dissertação apresentada ao Programa de Pós- graduação em Zootecnia da Universidade Federal de Santa Maria (UFSM) para obtenção do título de Mestre em Zootecnia.

\section{REFERÊNCIAS}

CAMARGO, A.C.S. et al. Níveis de energia metabolizável para Tambaqui (Colossoma macropomum) dos 30 aos 180 gramas de peso vivo. 1. Composição das carcaças. Revista Brasileira de Zootecnia, v.27, n.3, p.409-415, 1999

COLDEBELLA, I.; RADÜNZ NETO, J. Farelo de soja na alimentação de alevinos de jundiá (Rhamdia quelen). Ciência Rural, v.32, n.3, p.499-503, 2002.

EL-SAYED, A.F.M. Total replacement of fish meal with animal protein sources in Nile Tilapia, Oreochromis niloticus (L), feeds. Aquaculture Research, v.29, p.275-280, 1998.

GERI, G. et al. Body traits and chemical composition of muscle in the common carp (Cyprinus carpio L.) as influenced by age and rearing environment. Aquaculture, v.129, p.329-333, 1995.
GOMES, L.C. et al. Biologia do jundiá Rhamdia quelen (Teleostei, Pimelodidae). Ciência Rural, v.30, n.1, p.179185,2000

INSTITUTO ADOLFO LUTZ. Normas analíticas do Instituto Adolfo Lutz. v.I - Métodos químicos e físicos para análise de alimentos. São Paulo, 1985. 368p.

JOBLING, M. Environmental biology of fishes. New York: Chapman \& Hall, 1995. 455p.

JUSTI, K.C. et al. The influence of feed supply time on the fatty acid profile of Nile tilapia (Oreochromis niloticus) fed on a diet enriched with n-3 fatty acids. Food Chemistry, v.80, p. 489-493, 2003

KAUSHIK, S.J. et al. Partial or total replacement of fish meal by soybean protein on growth protein utilization, potential estrogenic or antigenic effects, cholesterolemia and flesh quality in rainbow trout, Oncorhynchus mykiss. Aquaculture, v.133, p.257-274, 1995.

KIM, M.K. et al. Effect of soybean meal and full-fat soybean for fish meal replacement on the growth performance of carp grower. Korean Journal Animal Nutrition Feeding, v.21, n.6, p.503-510, 1997.

LANARA. Métodos analíticos oficiais para controle de produtos de origem animal e seus ingredientes. I Métodos microbiológicos. Brasília, 1981. 250p.

LOVELL, R.T. Nutrition of Aquaculture species. Journal of Animal Science, v.69, p.4193-4200, 1991.

LOVELL, R.T. Use of soybean products in diets for aquaculture species. Journal Aquatic Products, v.2, p.27-52, 1988.

MELO, J.F.B. et al. Desenvolvimento e composição corporal de alevinos de jundiá (Rhamdia quelen) alimentados com dietas contendo diferentes fontes de lipídios. Ciência Rural, v.32, n.2, p.323-327, 2002 .

MEYER, G.; FRACALOSSI, D.M. Protein requirement of jundia fingerlings, Rhamdia quelen, at two dietary energy concentrations. Aquaculture, v.240, p.331-343, 2004.

MOHSEN, A.A.; LOVELL, R.T. Partial substitution soybean meal with animal protein sources in diets for channel catfish. Aquaculture, v.90, p.303-311, 1990.

MOYANO, F.J. et al. Nutritive value of diets containing a high percentage of vegetables proteins for trout, Oncorhyncus mykis. Aquatic Living Resources, v.5, p.21-39, 1992.

PEREIRA DA SILVA, E.M.; PEZZATO, L.E. Respostas da tilápia do Nilo (Oreochromis niloticus) à atratividade e palatabilidade de ingredientes utilizados na alimentação de peixes. Revista Brasileira de Zootecnia, v.29, n.5, p.1273-1280, 2000 .

PIAIA, R.; RADÜNZ NETO, J. Avaliação de diferentes fontes protéicas sobre o desempenho inicial de larvas do jundiá Rhamdia quelen. Ciência Rural, v.27, n.2, p.319-323, 1997.

PONGMANEERAT, $\mathrm{J}$. et al. Use of different protein meals as partial or total substitution for fish meal in carp diets. Nippon Suisan Gakkaishi, v.59, n.7, p.1249-1257, 1993 
RADÜNZ NETO, J. et al. Water re-use system of fingerling fishes in Brasil with emphasis on South american catfishes (Rhamdia quelen and R. sapo). Tropical Agriculture, v.64, p.2-6, 1987.

REFSTIE, S. et al. Feed consumption and conversion in Atlantic salmon (Salmo salar) fed diets with fish meal, extracted soybean meal or soybean meal with reduced content of oligosaccharides, trypsin inhibitors, lectins and soya antigens. Aquaculture, v.162, p.301-312, 1998.

SAS. Statistical Analisys System. User's Guide. Version 6.08. 4.ed. North Caroline, 1997. 846p.

SHIRAI, N. et al. Dietary and seasonal effects on the dorsal meat lipid composition of Japanese (Silurus asotus) and Thai catfish (Clarias macrocephalus) and hybrid Clarias macrocephalus and Clarias gariepinus. Comparative Biochemistry and Physiology Part A, v.132, p.609-619, 2002.
TACHIBANA, L.; CASTAGNOLLI, N. Custo na alimentação dos peixes: é possível reduzir mantendo a qualidade? Panorama da Aqüicultura, v.13, n.75, p.55-57, 2003.

TACON, A.G.J. Feed ingredients for warmwater fish: fish meal and other processed feedstuffs. FAO Fisheries. Rome: FAO, 1993. 64p. (Circular n. 856).

WEBSTER, C.D. et al. Growth and body composition of channel catfish (Ictalurus punctatus) fed diets containing various percentages of canola meal. Aquaculture, v.150, p.103-112, 1997.

WEBSTER, C.D. et al. Use of soybean meal as partial or total substitute of fish meal in diets for blue catfish (Ictalurus furcatus). Aquatic Living Resources, v.8, p.379-384, 1995.

WEBSTER, C.D et al. Effect of partially or totally replacing fish meal with soybean meal on growth of blue catfish (Ictalurus furcatus). Aquaculture, v.103, p.141-152, 1992. 